Aiza \& Roshimah, "Kejatuhan Pemerintahan menurut Pemikiran Ibnu Khaldūn," Afkār Vol. 18 Special Issue (2016): 89-114

\title{
KEJATUHAN PEMERINTAHAN MENURUT PEMIKIRAN IBN KHALDŪN DALAM KARYANYA AL-MUQADDIMAH
}

IBN KHALDŪN'S THOUGHT ON THE FALL OF A GOVERMENT IN HIS WORK AL-MUQADDIMAH

\author{
AizaMaslan@Baharudin*,Roshimah Shamsudin ** \\ *** Pusat Pengajian Ilmu Kemanusian. Universiti Sains \\ Malaysia. 11800. Pulau Pinang Malaysia.
}

Emel: **oshimah@usm.edu.my

\begin{abstract}
Khulasah
Ibn Khaldūn mencipta nama sebagai pemikir ulung dalam dunia intelektual Islam melalui penghasilan karya tersohornya al-Muqaddimah yang telah memberi sumbangan besar dalam bidang keilmuan Islam, khususnya merintis kajian ketamadunan sehingga ketokohannya turut diakui oleh sarjana Barat. Curahan ideanya yang segar dan asli dalam karya tersebut sarat dengan ilmu-ilmu yang dicerakinkan hingga menjadi dasar bukan sahaja kepada bidang tamadun bahkan merentasi pelbagai disiplin ilmu seperti sejarah, sains sosial, ekonomi dan politik. Meskipun dijulang sebagai seorang cendekiawan Islam terkemuka, Ibn Khaldūn tidak terlepas daripada kritikan-kritikan yang mendakwa beliau membawa pemikiran yang menjurus kepada ciri-ciri sekular dalam penulisannya. Justeru artikel ini bertujuan mengkaji pemikiran Ibn Khaldūn dalam al-Muqaddimah yang berkaitan dengan kejatuhan sesebuah pemerintahan di samping penumpuan kepada aspek keadilan dan kezaliman pemerintah. Kedua-dua aspek tersebut dianalisis berdasarkan nasnas daripada al-Qur'an, al-Sunnah dan pandangan ulama. Bagi mencapai objektif tersebut, kajian yang berbentuk kualitatif ini menjalankan kaedah pengumpulan data melalui kajian kepustakaan. Datadata tersebut dianalisis berdasarkan kaedah induktif
\end{abstract}


Aiza \& Roshimah, "Kejatuhan Pemerintahan menurut Pemikiran Ibnu Khaldūn," Afkār Vol. 18 Special Issue (2016): 89-114

dan deduktif. Dapatan kajian menunjukkan bahawa pemikiran Ibn Khaldūn dalam perspektif kejatuhan sesebuah pemerintahan terutamanya dari sudut keadilan dan kezaliman pemerintah adalah selaras dengan nas-nas yang thabit daripada al-Qur'an dan al-Sunnah.

Kata kunci: Kejatuhan pemerintahan, pemikiran, Ibn Khaldūn, al-Muqaddimah.

\begin{abstract}
Ibn Khaldūn made a distinguished name of himself as a thinker in the Islamic intellectual world by means of his renowned work entitled al-Muqaddimah that contributes immensely in the field of Islamic sciences, particularly in pioneering the study of civilization; and accordingly his scholastic works were recognized by the Western scholars. His ideas were fresh and original making his works replete with knowledge that has been assayed to not only being applied as a basis for civilization but also traversed to various other disciplines such as history, social science, economics and politics. Although honoured as a leading Islamic scholar, Ibn Khaldūn was not immune from criticism. There were claims that his philosophies were treading on the verge of secularism. As such, this article aims to scrutinize the thoughts of Ibn Khaldūn pertaining to the fall of a government as well as focusing on the aspects of justice and tyranny of a falling government. Both aspects are analyzed in accordance to the authorities confined in the al-Qur'an and the Hadith as well as the views of the scholars. In order to achieve the objectives, this qualitative study is conducted through data collection method, applying library research. These data are analyzed based on inductive and deductive methods. The findings of the analysis illustrate that the ideas of Ibn Khaldūn on of the fall of a government in particular from the points of justice and tyranny are in line with the provisions sourced from the al-Qur'an and the al-Sunnah.
\end{abstract}


Aiza \& Roshimah, "Kejatuhan Pemerintahan menurut Pemikiran Ibnu Khaldūn," Afkār Vol. 18 Special Issue (2016): 89-114

Keywords: Fall of a government, thought, Ibn Khaldūn, al-Muqaddimah.

\section{Pendahuluan}

Ketokohan Ibn Khaldūn sebagai pemikir Islam yang unggul tidak dapat dinafikan lagi. Gagasan pemikirannya terutama pemikiran peradabannya telah memberi sumbangan yang signifikan dalam pelbagai aspek keilmuan bukan sahaja kepada dunia Islam bahkan juga kepada dunia Barat. ${ }^{1}$ Pemikiran beliau yang terkandung dalam karya ulungnya al-Muqaddimah telah menjadi rujukan penting dalam pelbagai bidang ilmu umpamanya sejarah, ekonomi, politik dan pendidikan sehingga beliau dinobatkan dengan beberapa gelaran kesarjanaan seperti bapa ilmu sejarah, sosiologi, antropologi, ekonomi dan sains politik.

Namun menurut Amran Muhammad, dengan mengambil kira disiplin 'Ilm al- 'Umrān yang dirintis oleh Ibn Khaldūn, gelaran yang sewajarnya diberikan adalah Bapa Sains Peradaban. ' 'Ilm al-'Umrān telah terbukti menyerlahkan kehebatan pemikiran Ibn Khaldūn yang diakui mempunyai keupayaan ilmiah yang besar untuk menggarap dan mencerna komponen-kompenan yang lazimnya berasingan dalam disiplin-disiplin ilmu seperti individu dan sosial, institusi dengan negara, material dan

${ }^{1}$ Zaid Ahmad, "Ibn Khaldūn: Tradisi Ilmu dan Relevensinya dalam Wacana Kontemporari," dalam Ibn Khaldūn Pemikiran Ibn Khaldūn dan Relevensinya dalam Tamadun Kontemporari, ed. Azizan Baharudin et.al. (Kuala Lumpur: Pusat Dialog Peradaban Universiti Malaya, 2009), 3-4.

${ }^{2}$ Amran Muhammad, "Dari Fiqh al-Harakah kepada Fiqh al-Hadarah: Menghidupkan Tradisi Ibn Khaldūn dalam Masyarakat Islam Kontemporari," dalam Ibn Khaldūn Pemikiran Ibn Khaldūn dan Relevensinya dalam Tamadun Kontemporari, ed. Azizan Baharudin et.al. (Kuala Lumpur: Pusat Dialog Peradaban Universiti Malaya, 2009), 54. 
spiritual, sejarah dan geografi secara holistik dan bersepadu. $^{3}$

Konsep 'Umrān yang diperkenalkan oleh Ibn Khaldūn dalam karya al-Muqaddimah memberikan konotasi peradaban yang dikonsepsikan sebagai 'organisasi sosial'. Perkara ini bukanlah suatu perkara yang asing kerana al-Muqaddimah secara umumnya telah dianggap sebagai satu kajian terperinci mengenai peradaban manusia. ${ }^{4}$ Antara perkara yang menjadi tumpuan perbincangan Ibn Khaldūn dalam alMuqaddimah selain daripada kehidupan masyarakat primitif yang berpindah randah, ciri kehidupan masyarakat yang berperadaban tinggi, corak pemerintahan atau kerajaan termasuk sistem khalifah adalah perbincangan mengenai faktor-faktor pembinaan dan kejatuhan peradaban manusia. ${ }^{5}$

Dalam konteks kejatuhan peradaban manusia, Ibn Khaldūn mengaitkan kejatuhannya dengan pemerintah yang menerajui pucuk pimpinan sesebuah pemerintahan. Lebih khusus lagi, pemerintah yang mengabaikan agama sebagai asas pegangan akan menyumbang kepada keruntuhan sesebuah tamadun kerana agama adalah penyelamat. ${ }^{6}$ Oleh itu sudut pandang Islam menjadi antara rukun pemikiran Ibn Khaldūn.

Malah menurut Ahmad Zaki Berahim @ Ibrahim dan Norhayati Hamzah, metodologi Ibn Khaldūn

${ }^{3}$ Ibid., 54-55.

4 Aiza Maslan@ Baharudin, “Teori 'Umrān Ibn Khaldūn: Kajian Khusus Kejatuhan Peradaban Islam Melaka dan Kebangkitan Kuasa Portugis di Melaka," (Disertasi Sarjana Pengajian Peradaban, Fakulti Sastera dan Sains Sosial, Universiti Malaya, 2000), 47-48.

5 Ibid., 48.

6 Azmil Zainal Abidin, "Kajian Kemasyarakatan dan Ketamadunan (Ilmu 'Umrān) menurut Perspektif Usuluddin: Tumpuan Analitis Terhadap Muqaddimah Ibn Khaldūn," dalam Ibn Khaldūn Pemikiran Ibn Khaldūn dan Relevensinya dalam Tamadun Kontemporari, ed. Azizan Baharudin et.al. (Kuala Lumpur: Pusat Dialog Peradaban Universiti Malaya, 2009), 188. 
Aiza \& Roshimah, "Kejatuhan Pemerintahan menurut Pemikiran Ibnu Khaldūn," Afkār Vol. 18 Special Issue (2016): 89-114

memperlihatkan asas agama Islam apabila memperteguhkan pemikiran dan teorinya berkaitan dengan politik, ekonomi dan lain-lain berdasarkan nas-nas daripada al-Qur'an, hadis dan pandangan para Sahabat. Lantaran itu pemikiran beliau pada asasnya adalah pemikiran Islam. ${ }^{7}$

Justeru, penulisan ini bertujuan mengkaji beberapa aspek pemikiran Ibn Khaldūn berkaitan dengan kejatuhan sesebuah pemerintahan khususnya aspek keadilan dan kezaliman pemerintah dengan mengemukakan analisis berasaskan nas-nas daripada al-Qur'an dan al-Sunnah serta pandangan ulama.

\section{Latar belakang Ibn Khaldūn secara ringkas}

Nama penuh Ibn Khaldūn sebagaimana yang dicatat oleh beliau sendiri adalah 'Abd al-Raḥmān b. Muḥammad b. Muḥammad b. Muḥammad b. al-Ḥasan b. Muḥammad b. Jābir b. Muḥammad b. Ibrāhīm b. 'Abd al-Raḥmān b. Khaldūn. ${ }^{8}$ Susur galur salasilah keluarganya dikenal pasti bersambung dengan salah seorang Sahabat Nabi S.A.W iaitu Wā'il b. Hujr. ${ }^{9}$ Beliau dilahirkan pada 27 Mei 1332 di sebuah bandar yang dikenali dengan nama Tunis yang terletak di negara Tunisia yang merupakan kota ilmu terpenting di utara Afrika. ${ }^{10}$

7 Ahmad Zaki Berahim @ Ibrahim \& Norhayati Hamzah, "Pemikiran Perpindahan Pimpinan dan Tamadun Dalam Peradaban Manusia Menurut Ibn Khaldūn : Satu Analisis Penilaian," dalam Ibn Khaldūn Pemikiran Ibn Khaldūn dan Relevensinya dalam Tamadun Kontemporari, ed. Azizan Baharudin et.al. (Kuala Lumpur: Pusat Dialog Peradaban Universiti Malaya, 2009), 381.

${ }^{8}$ Ibn Khaldūn, Al-Ta'rīf bi Ibn Khaldūn wa Riḥlatuh Gharban wa Sharqan (Lubnan : t.tp, t.t ), 3.

9 Farid al-Attas, Ibn Khaldūn Makers of Islamic Civilization (Oxford: Oxford University Press, 2014), 2.

${ }^{10}$ Ratna Roshida Abd Razak et.al., "Legasi Pemikiran Ibn Khaldūn (1332-1395M) dalam Dunia Pendidikan," dalam Ibn Khaldūn Pemikiran Ibn Khaldūn dan Relevensinya dalam Tamadun Kontemporari, pnyt. Azizan Baharudin et.al. (Kuala Lumpur: Pusat Dialog Peradaban Universiti Malaya, 2009), 71-72. 
Ahli keluarganya berasal daripada selatan Tanah $\mathrm{Arab}^{11}$ yang dinyatakan secara spesifik oleh Farid al-Attas sebagai merujuk kepada kawasan Hadhramaut dalam negara Yaman. $^{12}$ Keluarga Khaldūn berhijrah ke Sepanyol pada tahun-tahun awal pembukaan Sepanyol oleh tentera Arab Muslim dengan menetap di sebuah tempat yang bernama Carmona sebelum berpindah ke Seville. Kaum keluarganya memainkan peranan yang penting dalam beberapa siri perang saudara yang meletus pada abad ke-9 sekaligus dianggap sebagai salah satu daripada tiga buah keluarga terpenting di bandar tersebut.

Penglibatan keluarga Ibn Khaldūn secara berterusan dalam menjawat beberapa jawatan tertinggi pentadbiran dan politik pada abad-abad berikutnya di bawah pemerintahan kerajaan 'Umayyah, al-Murabitun dan alMuwahhidūn selain berkhidmat dalam ketenteraan membuktikan bahawa Ibn Khaldūn datang daripada keluarga berkedudukan. ${ }^{13}$ Berikutan itu tidak hairanlah terdapat penulisan yang menyifatkan keluarga beliau sebagai golongan bangsawan. ${ }^{14}$ Di samping latar belakang keluarga yang terlibat dengan politik dan pentadbiran, mereka juga dikenali sebagai keluarga yang mementingkan ilmu pengetahuan. ${ }^{15}$ Bapanya merupakan individu yang bertanggungjawab memecahkan tradisi keluarganya apabila beralih arah daripada dunia politik kepada dunia keilmuan.

${ }^{11}$ Syed Omar Syed Agil, Ibn Khaldūn's Theory of Social Sciences and on the Rise and Fall of Nations, (Kuala Lumpur: INMIND, 1997), 5.

12 Farid al-Attas, Ibn Khaldūn Makers of Islamic Civilization, 2.

13 Khadijah Mohd Hambali, "Pemikiran Ibn Khaldūn dan Relevensinya dengan Islam Hadhari dalam Konteks Ketamadunan, Budaya dan Agama di Malaysia," dalam Ibn Khaldūn Pemikiran Ibn Khaldūn dan Relevensinya dalam Tamadun Kontemporari, ed. Azizan Baharudin et.al. (Kuala Lumpur: Pusat Dialog Peradaban Universiti Malaya, 2009), 109.

14 Syed Omar Syed Agil, Ibn Khaldūn's Theory of Social Sciences, 5.

15 Ibid. 
Jelas bahawa dua aspek penting melatari kehidupan keluarganya iaitu politik dan pendidikan. Berikutan itu tidak hairanlah mereka disifatkan sebagai eminent family of politicians and men of knowledge menurut Farid alAttas dan latar belakang ini merupakan antara salah satu elemen penting yang mempengaruhi pemikiran seseorang tokoh seperti Ibn Khaldūn selain daripada pengalaman peribadinya. ${ }^{16}$

Daripada segi keilmuan, ternyata Ibn Khaldūn mempunyai asas yang kukuh dalam bidang ilmu Islam. Buktinya, pendidikan awal beliau menunjukkan berlaku pembelajaran beberapa teras ilmu Islam seperti al-Qur'an, bahasa Arab, hadis dan fekah di samping mempelajari syair bergurukan beberapa tokoh tersohor Tunisia seperti Shams al-Dīn Muḥammad bin Jābir b. Sulțān Wādiyashī, Muhạmmad b. Abdullah al-Jayyānī dan Muhammad b. 'Abd al-Salām al-Hawwārī. ${ }^{17}$ Hasil pengajian tersebut, beliau dianugerahkan beberapa ijazah yang antaranya memberi autoriti kepada beliau menyampaikan ilmu dalam bidang bahasa dan undang-undang.

Namun guru yang memberi pengaruh yang paling besar terhadap perkembangan intelektualnya adalah Muḥammad b. Ibrāhīm al-Ābilī, pakar ilmu sains rasional. ${ }^{18}$ Beliau turut mendalami tradisi keilmuan yang diwarisi daripada pemikir Greek iaitu Aristotle dan Plato serta pemikir Islam, al-Farabī. Sumber ilmu yang diperolehinya diperkayakan lagi dengan catatan pengembara-pengembara Islam, sejarah perkembangan dan kejatuhan beberapa buah kerajaan Islam Timur Tengah dan pengalaman berhijrah ke beberapa buah negara.

${ }^{16}$ Farid al-Attas, Ibn Khaldūn Makers of Islamic Civilization, 1.

17 Syed Omar Syed Agil, Ibn Khaldūn's Theory of Social Sciences, 5.

18 Farid al-Attas, Ibn Khaldūn Makers of Islamic Civilization, 2.

19 H.K. Sherwani, Ibn Khaldūn's Science of Human Culture (Pakistan: Sh. Muhammad Ashraf, 1970), 71. 
Jelas bahawa latar belakang keluarga turut memberi impak terhadap hala tuju pemikiran beliau berkaitan dengan politik dan pendidikan seperti mana yang diungkapkan dalam mahakaryanya al-Muqaddimah.

\section{Penglibatan Ibn Khaldūn dalam Pentadbiran Kerajaan}

Ibn Khaldūn sendiri pernah terlibat dalam bidang politik dan pentadbiran kerajaan. Perkara ini dapat dilihat menerusi perkhidmatannya terhadap Sultan Mesir iaitu Sultan Barbuq ketika usia belasan tahun lagi. ${ }^{20}$ Penglibatan beliau dalam politik tidak terhad di negara Mesir sahaja, bahkan beliau pernah berkhidmat dalam pentadbiran politik negara di Tunisia, Maghribi dan Andalus. Suasana politik ketika kemunculan Ibn Khaldūn berada dalam keadaan yang bergolak. Masyarakatnya berhadapan dengan peperangan demi peperangan, komplot-komplot untuk menjatuhkan pemerintah dan pertukaran dinasti pemerintahan secara silih berganti. Keadaan ini menyebabkan kerjaya politik beliau agak tidak menentu. Khidmat beliau sering bertukar ganti dari satu kuasa pemerintahan kepada yang lain. ${ }^{21}$ Karier politik yang dipenuhi dengan jatuh bangun ini memberi peluang kepada Ibn Khaldūn menganalisis peristiwa-peristiwa yang berlaku di sekelilingnya.

Secara lebih spesifik, ketokohan Ibn Khaldūn dalam lapangan politik dapat dilihat melalui kepelbagaian jawatan yang pernah disandang olehnya, antaranya adalah seperti berikut:

i. Sāhib al-'Allāmah yang dilantik oleh Sultan Tunisia, Sultan Abū Ishāa II (1350);

20 Khadijah Mohd Hambali, Pemikiran Ibn Khaldūn dan Relevensinya Dengan Islam Hadhari Dalam Konteks Ketamadunan, Budaya dan Agama di Malaysia, 109.

21 Mi'raj Muhammad, "Ibn Khaldūn and Vico A Comparative Study," Islamic Studies, 19, III (1980): 195. 
Aiza \& Roshimah, "Kejatuhan Pemerintahan menurut Pemikiran Ibnu Khaldūn," Afkār Vol. 18 Special Issue (2016): 89-114

ii. Setiausaha Sultan Abū 'Inan di Fez Maghribi (1355);

iii. Setiausaha Sulit Sultan Salīm, Fez ( 1358);

iv. Ketua delegasi Sultan Muhammad V ke Granad bagi memeterai perjanjian perdamaian dengan pemerintah Kristian, Pedro di Seville, Sepanyol (1362);

v. Perdana Menteri (hājib) Sultan Abū Abdullah Muhammad di Bougie (1365-1356);

vi. Ketua Kadi Mazhab Maliki sebanyak enam kali antara tahun 1384-1402). ${ }^{22}$

Namun Ibn Khaldūn kemudiannya menarik diri daripada semua jawatan politik dan pentadbiran disebabkan minat yang mendalam terhadap bidang akademik dan kesarjanaan. Walau bagaimanapun, semua peristiwa yang berlaku sepanjang menggalas tugasnya seperti kekacauan, pergolakan politik dan komplotkomplot menentang kerajaan dirakamkan dalam karyanya, khususnya dalam bab tiga. Dalam bab berkenaan beliau menghuraikan undang-undang sosial yang mengawal kelahiran, perkembangan dan kejatuhan dinasti-dinasti serta peradaban manusia. ${ }^{23}$

Kenyataan ini diperkuatkan oleh pandangan Heinrich Simon yang menyatakan al-Muqaddimah bukan hanya penyelidikan saintifik beliau tetapi juga hasil daripada pengalaman politik yang dilaluinya. ${ }^{24}$ Justeru, ternyata bahawa pendedahan Ibn Khaldūn terhadap dunia politik melalui pengalaman dan pemerhatiannya sepanjang terlibat dalam pemerintahan kerajaan menyumbang kepada pembentukan pemikiran beliau.

Aiza Maslan@ Baharudin, Teori 'Umran Ibn Khaldūn, 45.

23 Ibid.

24 Heinrich Simon, Ibn Khaldūn's Science of Human Culture (Pakistan: Sh. Muhammad Ashraf, 1978), 29. 


\section{Kitaran Pemerintahan Menurut Ibn Khaldūn}

Ibn Khaldūn dalam perbincangannya mengenai peringkatperingkat perkembangan peradaban dalam karyanya alMuqaddimah didapati menyentuh mengenai kitaran pemerintahan. Menurut Ibn Khaldūn, pada peringkat pertama kelahiran sesebuah peradaban, iaitu sejurus selepas berlaku peralihan kuasa daripada tampuk pemerintahan sebelumnya, pemerintah menjadi contoh dan teladan kepada rakyat. Selain bersikap adil dan saksama dalam mempertahankan hak milik rakyatnya, pemerintah juga akan cuba menyesuaikan diri dengan sentimen dan kehendak rakyat serta berkongsi kuasa dengan mereka. Hasilnya, semangat 'așabiyyah yang telah diterjemahkan kepada beberapa istilah, seperti 'semangat kekitaan', esprit de corps, social solidarity dan group feeling dalam kalangan rakyat sangat kuat pada peringkat ini. ${ }^{25}$ Pendek kata, wujud hubungan timbal balik yang harmoni antara pemerintah dan juga rakyat.

Apa yang disuarakan oleh Ibn Khaldūn mengenai keadilan pemerintah sebagai tonggak keharmonian negara adalah selaras dengan nas daripada al-Qur'an dalam surah al-Nisā' ayat 58 yang secara umumnya menyeru kepada keadilan iaitu ayat yang bermaksud:

Sesungguhnya Allah menyuruh kamu menunaikan amanah kepada manusia dan apabila kamu berhukum maka hendaklah kamu menghukum dengan seadil-adilnya.

Ibn Kathīr mentafsirkan adil dalam ayat ini sebagai bermaksud mewujudkan kesamaan dan keseimbangan antara hak dan kewajipan dalam erti kata hak yang tidak boleh dikurangi disebabkan adanya kewajipan. Kezaliman lawan kepada keadilan wajib dijauhi. ${ }^{26}$ Hamka turut mengemukakan tafsiran yang hampir menyamai tafsiran

${ }^{25}$ Aiza Maslan@ Baharudin, Teori 'Umran Ibn Khaldūn, 53.

${ }^{26}$ Abū al-Fidā' 'Imād al-Dīn Ismā'îl b. Kathīr, Tafsīr al-Qur'ān al'Azìm (Beirut: Dār al-Kutub al-'Ilmīyyah, 1987), 7: 332. 
Ibn Kathīr, namun membawakannya dalam bentuk yang lebih terperinci iaitu sebagai menimbang sama berat, menyalahkan yang salah, membenarkan yang benar, mengembalikan hak kepada yang empunya dan jangan berlaku zalim aniaya. Adil lawannya zalim. ${ }^{27}$

Menurut Hamka lagi, ayat ini wajib dipegang oleh para penguasa yang memiliki kekuasaan memerintah urusan umat Islam. Para pemerintah dituntut melaksanakan dua dasar penting pemerintahan iaitu menyerahkan amanah kepada ahlinya dan menegakkan keadilan. $^{28}$ Nurdin Zainal berpandangan ayat al-Qur'an mengenai keadilan ini merangkumi makna yang luas dan meliputi pelbagai aspek termasuklah kepimpinan. Dalam konteks kepimpinan, keadilan yang diperintahkan oleh Allah kepada pemerintah di bumi ini adalah keadilan yang seimbang dalam erti kata keadilan yang dapat melahirkan kemaslahatan masyarakat sehingga dapat mencapai kemajuan. $^{29}$

Selain itu, terdapat nas yang jelas menerangkan tuntutan pelaksanaan keadilan oleh ketua negara Islam sebagaimana firman Allah dalam surah Sād ayat 26 yang bermaksud:

Wahai Dawud sesungguhnya Kami telah menjadikan kamu sebagai pemerintah di atas muka bumi, maka wajiblah kamu menghukum mereka dengan kebenaran dan janganlah kamu mengikuti hawa nafsu nescaya nanti ia akan menyesatkan kamu dari jalan Allah.

${ }^{27}$ Hamka, Tafsir al-Azhar (Singapura: Pustaka Nasional Pte Ltd, 1993), 5: 3951

${ }^{28}$ Hamka, Tafsir al-Azhar (Jakarta: Penerbit Pustaka Panjimas, 1983), 5: 140 .

${ }^{29}$ Nurdin Zainal, “ Dimensi Keadilan dalam al-Qur'an,” Seminar Kelas Mata Kuliah Pemikiran Politik Islam, Universitas Islam Negeri Alauddin Makassar (UIN), 2014. 
Menurut Hamka, ayat ini secara spesifiknya menjelaskan bahawa para penguasa seperti raja, sultan atau khalifah bertanggungjawab sepenuhnya menghukum dengan benar yakni adil. ${ }^{30}$ Walau bagaimanapun, ada juga pandangan yang menyatakan bahawa tuntutan keadilan dalam ayat tersebut tidak hanya ditujukan kepada kelompok sosial tertentu dalam masyarakat bahkan kepada setiap orang yang mempunyai kekuasaan memimpin orang lain. Namun tokoh seperti Muhammad 'Abduh membataskannya kepada pemerintah yang mempunyai kuasa politik. ${ }^{31}$ Selanjutnya Hamka berpandangan bahawa keadilan tidak dapat ditegakkan jika pemerintah dikuasai oleh hawa nafsu yang akan mengakibatkan berlakunya penyalahgunaan kuasa. ${ }^{32}$ Justeru, berlaku adil adalah salah satu amanah Allah kepada pemerintah yang perlu ditegakkan seadil-adilnya.

Selain daripada ayat al-Qur'an tersebut, terdapat beberapa hadis Nabi s.a.w yang memberi penekanan terhadap keadilan pemerintah. Dalam sebuah riwayat hadis yang sahih, pemimpin yang adil merupakan golongan pertama yang disebut oleh Nabi s.a.w antara tujuh golongan yang akan dinaungi oleh Allah pada hari Akhirat :

Tujuh golongan yang akan dinaungi oleh Allah di bawah naungan-Nya pada hari yang tiada naungan melainkan naungan-Nya: pemerintah yang adil, pemuda yang mengabdikan dirinya untuk beribadah kepada Tuhannya, lelaki yang hatinya tergantung di masjid..... ${ }^{33}$

\footnotetext{
${ }^{30}$ Hamka, Tafsir al-Azhar, (1993), 8 : 6172.

${ }^{31}$ Nurdin Zainal, Dimensi Keadilan dalam al-Quran, 11-12.

${ }^{32}$ Hamka, Tafsir al-Azhar, 8: 6172.

33 Ibn Hajar al-'Asqalānī, Fatḥ al-Bārī bi Syarh Ṣahīh al-Bukhārī, Kitāb al-Azān, Bāb Man Jalasa fī al-Masjid Yantaziir al-Șalāh, Hadis No. 660, ed. 'Abd al-'Azīz b. Bāz (Beirut: Dār al-Fikr, 2012), 2 :1335.
} 
Menurut Ibn Hajar, pemerintah dalam hadis tersebut merujuk kepada pemerintah wilayah yang besar termasuklah sesiapa sahaja yang mempunyai kuasa memerintah urusan umat Islam. Pemerintah yang adil selanjutnya ditafsirkan oleh beliau sebagai pemerintah yang mengikut perintah Allah dengan meletakkan sesuatu pada tempatnya tanpa berlebih dan berkurang. Sebutan pemerintah yang adil didahulukan dalam hadis berkenaan berasaskan manfaat umum yang dibawa olehnya. ${ }^{34}$ Berdasarkan perbincangan di atas, ternyata pandangan Ibn Khaldūn mengenai pemerintahan yang adil sebagai penyumbang kepada kestabilan negara adalah berdasarkan nas-nas daripada al-Qur'an dan hadis.

Selanjutnya, selepas melalui fasa pemerintahan yang adil dan saksama, berlaku perubahan terhadap pendekatan pemerintah dalam erti kata pemerintah berusaha untuk memonopoli kuasa dan menubuhkan kuasa mutlak mereka. Pemantauan rapi dilakukan agar tidak berlaku sebarang rampasan kuasa atau penglibatan diri dalam pemerintahan kerajaan daripada pihak musuh ataupun saudara mara sendiri. Pada peringkat ini, pemerintahan bercorak kuku besi mengambil tempat dan ternyata berjaya menewaskan musuh-musuhnya. Kekuatan semangat 'asabiyyah pada peringkat ini mula mempamerkan tanda-tanda awal kegoyahan. ${ }^{35}$

Menurut Ibn Khaldūn, apabila pemerintah berjaya memonopoli kuasa dan dibelenggu dengan ketamakan terhadap kuasa, negara memasuki peringkat kemewahan dan kesenangan. Berikutan itu, pemerintah memperkenalkan sistem cukai bagi menampung perbelanjaan negara yang semakin meningkat. Pendapatan yang meningkat membolehkannya berbelanja dengan boros. Golongan pemerintah dan rakyat mula mengubah

\footnotetext{
${ }^{34}$ Ibid., 1336.

${ }^{35}$ F. Rosenthal, The Muqaddimah: An Introduction to History (New Jersey: Princeton University Press, 1958), 2: 114.
} 
cara hidup kepada bermewah-mewah. Peringkat ini merupakan masa untuk memuaskan kehendak nafsu. ${ }^{36}$

Pada peringkat seterusnya, Ibn Khaldūn berpandangan pemerintah berpuas hati dengan apa-apa yang telah dibina oleh pemerintah terdahulu apabila negara atau peradaban memasuki fasa keamanan dan kedamaian. Beliau meniru gaya hidup pemerintah sebelumnya untuk menikmati kesenangan hidup, melupai perjuangan dan susah payah yang dilalui untuk menikmati keadaan damai tersebut. Pemerintah juga berpuas hati dengan apa yang telah dicapai dan percaya bahawa kemewahan hidup dan peradaban yang terbentuk tanpa memerlukan usaha yang gigih. ${ }^{37}$

Namun apabila kemewahan sampai ke peringkat kemuncak, menurut Ibn Khaldūn akan berlaku pembaziran dan pemborosan. Hasil mahsul negara digunakan untuk tujuan keseronokan dan hiburan. Senario ini akan merosakkan masyarakat, melemahkan fizikal dan mengakibatkan keruntuhan moral. Keadaan ini bertambah buruk apabila pemerintahan kerajaan dikendalikan oleh para pegawai yang tidak berkebolehan dan berkeperibadian buruk. Para pengikut pemerintah sebelumnya yang berkelayakan dipinggirkan daripada tampuk pemerintahan. Tindakan ini mengakibatkan timbul perasaan benci dan tidak puas hati dalam kalangan rakyat serta mendorong mereka untuk tidak memberikan sokongan kepada pemerintah yang baru.

Pada peringkat ini pemerintah juga sering mengabaikan hal ehwal pentadbiran negara, mengenakan cukai yang melampaui batas dan tidak membayar gaji kepada golongan tentera. Semangat 'așabiyyah yang dipupuk pada peringkat awal telah hilang peranannya. Pada peringkat ini, sesebuah peradaban dilanda penyakit

\footnotetext{
${ }^{36}$ Ibid., I: 354.

${ }^{37}$ Aiza Maslan@ Baharudin, Teori 'Umran Ibn Khaldūn, 54.
} 
yang begitu kronik dan tidak dapat dirawati lagi. Lantas, peradaban menjadi mangsa keganasan dalaman dan luaran. Kemusnahan melanda peradaban tersebut dan akan digantikan dengan sebuah peradaban baru. ${ }^{38}$

\section{Kejatuhan Pemerintahan Menurut Ibn Khaldūn}

Ibn Khaldūn mengetengahkan idea bahawa sesebuah pemerintahan atau peradaban tidak akan runtuh atau mati secara mengejut, bahkan proses berkenaan akan berlaku secara beransur-ansur. Dengan kata lain, sesebuah negara secara semula jadi membawa bersama-samanya benihbenih kemusnahan sendiri semenjak detik awal kelahirannya. Dalam konteks ini, terdapat dua faktor yang membawa kejatuhan sesebuah pemerintahan, iaitu faktor dalaman dan faktor luaran. Antara faktor dalaman tersebut ialah kelunturan semangat 'așabiyyah, pembentukan terlalu banyak kumpulan 'așabiyyah, kezaliman dan ketidakadilan sosial, kemewahan yang melenyapkan kesedaran beragama dan ketidakstabilan politik dan kelemahan pemerintah. ${ }^{39}$

Menurut Ibn Khaldūn, sering terjadi dalam pemerintahan sesebuah negara apabila para wazir atau menteri akan menguasai takhta kerajaan setelah raja yang memerintah mangkat dan putera raja yang masih kecil dilantik sebagai pewaris takhta. Wazir atau menteri berkenaan memperlihatkan bahawa beliaulah yang dipertanggungjawabkan untuk mengawal kedudukan raja yang masih kecil itu dan kesempatan tersebut akan digunakan bagi mendapatkan kedaulatan untuk berkuasa penuh. Beliau juga bertindak memanjakan putera raja yang masih kecil itu dengan kehidupan yang bersenanglenang dan berusaha menurut segala kehendak hati putera raja itu bagi melalaikan putera raja daripada memikirkan soal pentadbiran negara.

\footnotetext{
${ }^{38}$ Ibid., 54-55.

${ }^{39}$ F. Rosenthal, The Muqaddimah: An Introduction to History, 1: 336.
} 
Keyakinan penuh diberikan kepada raja bahawa tugas raja di dalam kerajaan hanyalah bersemayam di atas singgahsana yang indah, disapa dengan gelaran yang indah dan berseronok dengan gundik-gundiknya. Suasana ini akan melahirkan pemerintah yang lemah akhlak. Sebagai akibatnya, menteri mengambil alih kuasa kepimpinan dan pengaruhnya melebihi putera raja itu sendiri. Lebih malang lagi, beliau bertindak mengekalkan kuasa tersebut secara turun-temurun kepada anggota keluarganya pula. ${ }^{40}$

Kadang kala berlaku keadaan yang mana putera raja yang tersisih dan dinafikan hak untuk berkuasa mula menyedari keadaan tersebut dan berusaha untuk merampas hak keadaulatan untuk dirinya dan keluarga. Sering juga berlaku dalam sesebuah dinasti atau peradaban, perebutan dan rampasan kuasa dalam kalangan putera raja. Persengketaan yang berlaku kadang kala sampai ke tahap bunuh-membunuh sesama saudara. Mereka sanggup menggunakan apa-apa cara sekalipun bagi memiliki kuasa mutlak.

Mereka meninggalkan kehidupan padang pasir dan tahan lasaknya serta mencari kekuasaan melalui saingan sengit untuk menjadi pemimpin. Ini menyebabkan ada di antara mereka yang sanggup bunuh-membunuh. Raja telah bertindak menghalang perbuatan mereka dengan menghukum bunuh para pendekar dan para pembesar mereka. Maka para amir dan pembesar tidak lagi wujud, sedangkan jumlah pengikut dan orang bawahannya semakin bertambah. Tindakan sebegini telah menumpulkan sudut-sudut yang menjadi ketajaman negara, serta mengurangkan kekuatannya. Terjadilah keruntuhan pertama pada negara, iaitu keruntuhan melalui tentera dan pertahanan negara. ${ }^{41}$

40 Ibn Khaldūn, Mukadimah Ibn Khaldūn (Kuala Lumpur: Dewan 41 Ibid. 
Apabila negara dilanda masalah dalaman, kawalan terhadap pertahanan sesebuah negara pasti akan terabai. Tanah-tanah jajahan akan mula melakukan pemberontakan demi pemberontakan dalam usaha untuk membebaskan diri. Tindakan berkenaan akan melemahkan kekuatan negara yang terungkap menerusi pengecilan garis sempadan dan jajahan takluk. Suasana ini mempercepat lagi proses kejatuhan sesebuah peradaban. ${ }^{42}$

Ibn Khaldūn turut memperkenalkan konsep kezaliman (zulm) dan ketidakadilan. Pada pandangan beliau, berleluasanya kezaliman dan ketidakadilan adalah penyumbang paling utama kepada keruntuhan sesebuah peradaban kerana menurut beliau kezaliman dan ketidakadilan memusnahkan perkembangan kecerdasan manusia dari segi fizikal dan mental, sekali gus membunuh semangat untuk menyara kehidupan. Apabila semangat ini luntur, rakyat akan mengelakkan diri daripada berusaha untuk mencapai sebarang matlamat dalam kehidupan dan perkara tersebut akan melemahkan sistem ekonomi negara yang akhirnya melemahkan sesebuah peradaban. ${ }^{43}$

Kezaliman dan ketidakadilan yang dimaksudkan oleh Ibn Khaldūn dikategorikan sebagai sebarang bentuk penyalahgunaan kuasa, penyalahgunaan harta orang lain, menggunakan buruh paksa, menafikan hak orang lain dan menekankan dakwaan yang tidak benar ke atas orang yang tidak bersalah. Oleh kerana kezaliman merupakan kekuasaan yang eksklusif bagi orang-orang yang gagah dan berkuasa, Ibn Khaldun mengingatkan golongan pemerintah agar tidak menggunakan sebarang bentuk kekerasan dan paksaan ke atas rakyat.

Bentuk kezaliman dan ketidakadilan sosial adalah berbeza antara satu sama lain dari aspek tingkat

\footnotetext{
${ }^{42}$ Rosenthal, The Muqaddimah: An Introduction to History, II: 126.

43 George S. Firzly, Ibn Khaldūn: A Socio-Economic Study (Tesis Ijazah Doktor Falsafah, University of Utah, 1973), 241-242.
} 
kemusnahan yang diakibatkan kepada sesebuah peradaban dan bentuk yang paling buruk ialah paksaan bekerja terhadap rakyat dan monopoli ekonomi oleh golongan pemerintah kerana mereka bertindak dengan membeli barangan pada kadar harga yang rendah dan menjualnya pada kadar yang tinggi. Pengecualian membayar cukai juga merugikan negara sekali gus menjejaskan kelangsungan sesebuah peradaban. ${ }^{44}$

Oleh yang demikian, kezaliman adalah salah di sisi agama dan dikritik keras oleh syariah kerana ia mencegah wujudnya 'salam' (keamanan) dan membawa kepada kerosakan dan kehancuran peradaban yang akhirnya mendorong kepada berlakunya penghapusan manusia.

Dalam konteks kezaliman, terdapat banyak ayat alQur'an yang berkaitan dengannya. Salah satu daripadanya ialah ayat 18 dalam surah Hūd yang bermaksud:

Dan siapakah yang lebih zalim daripada orang yang mengada-adakan atas nama Allah suatu pendustaan. Mereka itu akan dihadapkan ke hadapan Tuhan mereka dan akan berkata saksisaksi 'inilah orang-orang yang berdusta atas nama Tuhan mereka'. Ketahuilah sesungguhnya laknat Allah ke atas orang-orang yang zalim.

Perkataan zalim dalam ayat di atas ditafsirkan oleh Hamka sebagai bermaksud gelap, antonim kepada terang. Ini bermakna orang-orang yang zalim tidak mengikuti jalan terang yang telah ditunjukkan oleh Allah melalui perantaraan nabi-nabi dan kitab-kitab suci-Nya, malah menghindari jalan yang terang dengan memilih jalan yang gelap dengan sengaja. Atas dasar itu, menurut Hamka mereka berhak mendapat kutukan Allah. ${ }^{45}$

\footnotetext{
44 Rosenthal, The Muqaddimah: An Introduction to History, II: 108,302 .

${ }^{45}$ Hamka Tafsir al-Azhar, 12: 32.
} 
Malahan dalam tafsiran ayat sebelumnya, Hamka didapati menyentuh mengenai kezaliman Firaun sebagai contoh pemerintah yang melakukan kebatilan, korupsi, penindasan golongan yang lemah, rasuah dan perampasan hak orang lain. Kezaliman yang dilakukan oleh pemerintah seperti Firaun menyebabkannya dihumban ke dalam neraka sebagai balasan kepada perbuatannya di dunia. ${ }^{46}$ Jelas bahawa pemerintah yang zalim antara golongan yang mendapat laknat Allah.

Selaras dengan tafsiran Hamka di atas, terdapat sebuah hadis riwayat al-Bukhārī yang menyifatkan kezaliman sebagai kegelapan namun dengan merujuk kepada kegelapan di Akhirat iaitu hadis yang bermaksud: "kezaliman adalah kegelapan-kegelapan pada hari Kiamat.",47

Dalam mensyarahkan hadis ini, Ibn Hajar menukilkan pandangan Ibn al-Jawzī dalam menerangkan ruang lingkup kezaliman yang merangkumi dua jenis kemaksiatan iaitu pengambilan harta orang lain tanpa hak dan pelanggaran hak-hak Allah. Menurut Ibn Hajar, maksiat dalam konteks kezaliman adalah lebih berat berbanding dengan perkara-perkata lain kerana lazimnya situasi kezaliman melibatkan penindasan terhadap orang yang daif yang tidak berupaya untuk meraih kemenangan. Beliau selanjutnya menerangkan bahawa kezaliman berpunca daripada hati yang gelap dalam erti kata hati yang disinari dengan petunjuk dan cahaya akan membawa kepada ketakwaan yang boleh menewaskan kegelapan kezaliman orang yang zalim. ${ }^{48}$

46 Ibid., 27-28.

47 Muhammad b. Ismā‘̄il al-Bukhārī Sahīh al-Bukhārī, Kitāb alMazālim, Bāb al-Zulm Zulumāt Yaum al-Qiyāmah, Hadis No. 2447 (Beirut: Dār Ibn Kathīr, 2002), 592.

${ }^{48}$ Ibn Hajar, Fatḥ al-Bārī bi Syarh Sahīh al-Bukhārī, Kitāb al-Maz̄ālim, Bāb al-Zulm Zulumāt Yaum al-Qiyāmah, Hadis No. 2447, 5: 297. 
Malahan terdapat sebuah hadis qudsī riwayat Muslim yang menerangkan mengenai pengharaman kezaliman iaitu hadis yang bermaksud: "Sesungguhnya Allah Taala telah berfirman: wahai Hamba-Ku sesungguhnya Aku haramkan kezaliman ke atas diri-Ku dan Aku jadikannya sebagai haram antara sesama kamu maka janganlah kamu saling menzalimi..."49 Hadis ini menurut al-Nawawī menunjukkan bahawa zalim adalah sifat keji yang diharamkan oleh Allah ke atas diri-Nya dan hambahamba-Nya. Sesiapa yang melakukan kezaliman bererti beliau telah melampaui batasan yang telah digariskan oleh Allah s.w.t. ${ }^{50}$

Selain itu terdapat sebuah hadis yang menunjukkan Allah memberi peringatan keras kepada pemimpin yang tidak amanah dalam memimpin hal ehwal rakyatnya. Hadis riwayat Muslim tersebut bermaksud: "Tidak ada seorang hambapun yang mendapat amanah dari Allah untuk memimpin rakyat, lalu ia meninggal pada hari meninggalnya di dalam keadaan mengkhianati rakyatnya melainkan Allah telah mengharamkan ke atasnya syurga" ${ }^{51}$ Hadis ini menurut al-Nawawī memberikan dua tafsiran iaitu pemerintah yang zalim diharamkan syurga dengan kekal dalam neraka atau dihalang masuk syurga bersama orang-orang yang berjaya memasukinya dengan dilewatkan azab bagi mereka sama ada di neraka atau ketika hisab. ${ }^{52}$ Jelas bahawa pemerintah yang zalim tidak akan terlepas daripada seksaan Allah di hari Akhirat.

49 Ab̄̄ al-Ḥusayn Muslim b. al-Hajjāj al-Naisābūri, Saḥịh Muslim, Hadis No. 2577, ed. Muḥammad Fu'ad 'Abd al-Bāqī (Kaherah: Dār al-Hadīth, 2010), $2: 270$.

50 Al-Nawaw $\overline{1}$, Hadis 40 Imam al-Nawawi, http://www.afghanenjoyislam.com/books/Farsi\%20Books/hadith/40Hadith_nawawi-eng.pdf., dicapai 15 November 2015.

${ }^{51}$ Muslim, Saḥ̄h Muslim, Kitāb al-Imārah, Bāb Faḍīlah al-Imām al'Ādil wa 'Uqūbah al-Jā'ir, Hadis No. 1829, 2: 292.

52 Muhib al-Dīn Abi Zakariyā Yahyā b. Sharaf al -Nawawī, Șaḥ̄h Muslim bi Syarḥ al-Nawawī, Kitāb al-Imārah, Bāb Faḍīlah al-Imām 
Rasuah atau korupsi merupakan suatu gejala yang mudah tersebar dan gejala tersebut mampu melumpuhkan peraturan sosio ekonomi sesebuah peradaban. Rasuah juga menggugat pengagihan kekayaan secara teratur, mengkayakan orang-orang yang tidak jujur dan memiskinkan orang-orang yang jujur. Fitnah yang merupakan satu usaha mengadakan sesuatu keburukan terhadap diri orang lain tanpa bukti yang kukuh atau menokok tambah berita yang bertujuan untuk merosakkan nama baik seseorang itu boleh menimbulkan huru-hara dan pertumpahan darah yang berpanjangan, mengorbankan banyak nyawa dan harta benda. ${ }^{53}$

Untuk mempertahankan kedudukannya dan kepentingannya, seseorang pemerintah memaksa dirinya untuk bergabung dengan para pengikut yang baru. Orangorang luar inilah yang diberikan perhatian lebih dengan segala keperluan dipenuhi. Mereka dikurniakan kedudukan yang tinggi, menghalangi kumpulan serta rakyatnya sendiri daripada mendapatkan kedudukan yang sebenarnya menjadi milik mereka. Rakyat juga disisih daripada jawatan yang suatu ketika dahulu menjadi hak milik mereka. Golongan pemerintah bertindak 'menganakemaskan' para pengikutnya yang baru. Beliau turut 'memilih bulu' dalam memberikan ganjaran dan penghormatan. ${ }^{54}$

Hal yang serupa melanda generasi seterusnya kerana mereka mengikuti jejak langkah generasi sebelumnya. Perasaan hamba rakyat dibangkitkan oleh perasaan jijik dan sikap permusuhan terhadap pemerintah. Mereka membenci pemerintah dan menunggu masa untuk menjatuhkannya. Lantaran itu, semangat 'așabiyyah

al-'Ādil wa 'Uqūbah al-Jā'ir, Hadis No. 1829 (Kaherah: al-Maṭba'ah al-Mișriyyah bi al-Azhar, 1929), 520.

${ }^{53}$ Rosenthal, The Muqaddimah: An Introduction to History, I: 297.

${ }^{54}$ The Oxford Encyclopedia of The Modern Islamic World, (1995), II: 140. 
semakin lemah dari satu generasi ke satu generasi. Keadaan ini merupakan suatu mala petaka bagi negara dan peradaban ibarat 'duri dalam daging'. Kesemua ini membuka jalan ke arah kehancuran peradaban dan memperlihatkan berjangkitnya suatu penyakit yang amat sukar diubati. ${ }^{55}$ Ibn Khaldun believed that the weakening of the 'asabiyyah among civilized people indicates the approaching suicide of the society as a whole, ${ }^{56}$

Walaupun sesebuah peradaban tetap dapat bertahan dan meneruskan hayat di dalam situasi sebegini namun, its substance dwindles like natural heat in a body that lack nourishment. Eventually the state reaches its destined time'. ${ }^{57}$

Kewujudan dan kemunculan pelbagai kelompok 'așabiyyah ditanggapi oleh Ibn Khaldūn sebagai salah satu penyebab yang bukan sahaja menghalang perkembangan sesebuah negara dan peradaban, tetapi juga melancarkan keruntuhan dan kejatuhannya. Beliau percaya bahawa setiap kumpulan mempunyai kepentingan dan ideologi tersendiri yang berbeza dengan kelompok-kelompok yang lain. Kepentingan dan ideologi tersebut bukan sekadar berbeza, tetapi dalam banyak keadaan bertentangan antara satu sama lain. Percanggahan kepentingan dan ideologi ini akan mencetuskan konflik dan membawa kepada peperangan.

Implikasinya, akan tercetusnya ketidakstabilan sosial dan politik yang akan membawa perpecahan dalaman negara dan peradaban kerana menurut Ibn Khaldūn kestabilan sosial dan politik merupakan prasyarat kepada perkembangan dan pertumbuhan negara dan peradaban. Di samping itu, memandangkan kelompok-kelompok 'așabiyyah ini tidak mempunyai pertalian darah secara

\footnotetext{
${ }^{55}$ Rosenthal, The Muqaddimah: An Introduction to History, I:332-336.

${ }^{56}$ The Oxford Encyclopedia of The Modern Islamic World, (1995), II: 140.

${ }^{57}$ Rosenthal, The Muqaddimah: An Introduction to History, II: 122.
} 
langsung dengan golongan pemerintah, kekuatan semangat 'așabiyyah semakin terhakis. Perasaan cinta akan negara dan peradaban tidak wujud di hati mereka. Jika ada pun, sedikit dan tidak dapat menjamin untuk mereka berusaha mempertahankan kedaulatan negara dan peradaban. $^{58}$

Menurut Ibn Khaldūn, kemenangan dan kekuasaan sesebuah negara atau pasukan dalam sesebuah peperangan adalah berpunca daripada kemujuran dan kesempatan. Pada kebiasaannya, kemenangan sesebuah pasukan bergantung kepada gabungan beberapa faktor luaran seperti memiliki bilangan anggota tentera terlatih, mempunyai alat persenjataan yang bermutu tinggi, bijaksana dalam menyusun barisan tempur dan menggunakan taktik yang betul.

Kemenangan semakin mudah dicapai apabila faktor luaran ditokok pula dengan faktor terselindung seperti tipu daya manusia, seperti tersebarnya desas-desus yang menyebabkan berlakunya perbuatan berpaling tadah dalam kalangan rakyat. ${ }^{59}$ Berdasarkan perbincangan di atas jelas bahawa pelbagai faktor yang menyumbang kepada kejatuhan sesebuah pemerintahan.

\section{Kesimpulan}

Pemikiran Ibn Khaldūn melalui karya al-Muqaddimah khususnya yang berkaitan dengan pemerintahan merupakan reflek daripada pengalaman beliau sendiri selain daripada pemerhatian terhadap suasana politik yang mewarnai zaman kehidupannya. Dalam konteks kejatuhan pemerintahan, Ibn Khaldūn melihat dasar pemerintah memainkan peranan yang sangat penting untuk memastikan tempoh hayat kelangsungan sesebuah pemerintahan. Pemerintahan yang adil dan saksama akan membawa keharmonian dan kestabilan kepada sesebuah

${ }^{58}$ Ibid., I: 332-336.

${ }^{59}$ Ibnu Khaldun, Mukadimah Ibn Khaldūn, 331-332. 
negara manakala kezaliman mengundang kehancuran sesebuah negara dengan lebih pantas. Isu keadilan dan kezaliman yang disuarakannya selaras dengan pandangan Islam itu sendiri.

\section{Rujukan}

Ahmad Zaki Berahim @ Ibrahim \& Norhayati Haji Hamzah. "Pemikiran Perpindahan Pimpinan dan Tamadun Dalam Peradaban Manusia Menurut Ibn Khaldūn: Satu Analisis Penilaian." Dalam Ibn Khaldūn Pemikiran Ibn Khaldūn dan Relevensinya dalam Tamadun Kontemporari, ed. Azizan Baharudin et.al. Kuala Lumpur: Pusat Dialog Peradaban Universiti Malaya, 2009.

Aiza Maslan@Baharudin. “Teori 'Umran Ibn Khaldūn: Kajian Khusus Kejatuhan Peradaban Islam Melaka dan Kebangkitan Kuasa Portugis di Melaka." Tesis Sarjana Pengajian Peradaban, Fakulti Sastera dan Sains Sosial. Kuala Lumpur: Universiti Malaya, 2000.

Amran Muhammad. "Dari Fiqh al-Harakah kepada Fiqh al-Hadārah: Menghidupkan Tradisi Ibn Khaldūn dalam Masyarakat Islam Kontemporari." Dalam Ibn Khaldūn Pemikiran Ibn Khaldūn dan Relevensinya dalam Tamadun Kontemporari, ed. Azizan Baharudin et.al. Kuala Lumpur: Pusat Dialog Peradaban Universiti Malaya, 2009.

Azmil Zainal Abidin. Kajian Kemasyarakatan dan Ketamadunan (Ilmu 'Umran) menurut Perspektif Usuluddin: Tumpuan Analitis Terhadap Muqaddimah Ibn Khaldūn. Dalam Ibn Khaldūn Pemikiran Ibn Khaldūn dan Relevensinya dalam Tamadun Kontemporari, ed. Azizan Baharudin et.al. Kuala Lumpur: Pusat Dialog Peradaban Universiti Malaya, 2009.

Al-Bukhārī, Muḥammad bin Ismā'îl. Șaḥịh al-Bukhārī. Beirut: Dār Ibn Kathīr, 2002. 
Farid al-Attas. Ibn Khaldūn Makers of Islamic Civilization. Oxford: Oxford University Press, 2014.

Firzly, George S. Ibn Khaldūn: A Socio-Economic Study. Tesis Ijazah Doktor Falsafah. University of Utah, 1973. Hamka. Tafsir al-Azhar. Jakarta: Penerbit Pustaka Panjimas, 1983.

Hamka. Tafsir al-Azhar. Singapura: Pustaka Nasional Pte Ltd, 1993.

Ibn Hajar al-'Asqalānī. Fatḥ al-Bārī bi Syarh Șaḥ̄ḥ alBukhārī, ed. 'Abd al-'Azīz b. Bāz. Beirut: Dār al-Fikr, 2012.

Ibn Kathīr, Abū al-Fidā' 'Imād al-Dīn Ismā'îl. Tafsīr alQur'ān al-'Azìm. Beirut: Dār al-Kutub al-'Ilmiyyah, 1987.

Ibn Khaldūn. Al-Ta'rīf bi Ibn Khaldūn wa Rihlatuh Gharban wa Sharqan. Lubnan: t.tp, t.t.

Ibn Khaldūn. Mukadimah Ibn Khaldūn. Kuala Lumpur: Dewan Bahasa dan Pustaka, 1995.

Khadijah Mohd Hambali. "Pemikiran Ibn Khaldūn dan Relevensinya Dengan Islam Hadhari Dalam Konteks Ketamadunan, Budaya dan Agama di Malaysia." Dalam Ibn Khaldūn Pemikiran Ibn Khaldūn dan Relevensinya dalam Tamadun Kontemporari, ed. Azizan Baharudin et.al. Kuala Lumpur: Pusat Dialog Peradaban Universiti Malaya, 2009.

Muhammad, Mi'raj, "Ibn Khaldūn and Vico A Comparative Study," Islamic Studies 19: III, 1980.

Muslim, Abī al-Husayn b. al-Hajjāj al-Naisāburī. Saḥịh Muslim, ed. Muhammad Fu'ad 'Abd al-Bāqī. Kaherah: Dār al-Hadīth, 2010.

Al-Nawawī, Muhịb al-Dīn Abī Zakariyā Yaḥyā b. Sharaf. Sah̄̄h Muslim bi Syarh al-Nawawī. Kaherah: alMațba'ah al-Mișriyyah bi al-Azhar, 1929.

Al-Nawawī, Muhịb al-Dīn Ab̄̄ Zakariyā Yahyyā b. Sharaf. Hadis $\quad 40 \quad$ Imam al-Nawawī. 
http://www.afghanenjoyislam.com/books/Farsi\%20Boo ks/hadith/40-Hadith_nawawi-eng.pdf.

Nurdin Zainal. "Dimensi Keadilan dalam al-Quran." Seminar Kelas Mata Kuliah Pemikiran Politik Islam. Universitas Islam Negeri Alauddin Makassar (UIN), 2014.

Ratna Roshida Abd Razak et.al. "Legasi Pemikiran Ibn Khaldun (1332-1395M) dalam Dunia Pendidikan."

Dalam Ibn Khaldūn Pemikiran Ibn Khaldūn dan Relevensinya dalam Tamadun Kontemporari, ed. Azizan Baharudin et.al. Kuala Lumpur: Pusat Dialog Peradaban Universiti Malaya, 2009.

Rosenthal, F. The Muqaddimah: An Introduction to History. New Jersey: Princeton University Press, 1958.

Sherwani, H. K. Ibn Khaldūn and His Politico-Economic Thought. Pakistan: Sh. Muhammad Ashraf, 1970.

Simon, Heinrich. Ibn Khaldūn's Science of Human Culture. Pakistan: Sh. Muhammad Ashraf, 1978.

Syed Omar Syed Agil. Ibn Khaldūn's Theory of Social Sciences and On the Rise and Fall of Nations. Kuala Lumpur: INMIND, 1997.

The Oxford Encyclopedia of The Modern Islamic World, $11,1995$.

Zaid Ahmad. "Ibn Khaldūn: Tradisi Ilmu dan Relevensinya dalam Wacana Kontemporari." Dalam Ibn Khaldūn Pemikiran Ibn Khaldūn dan Relevensinya dalam Tamadun Kontemporari, ed. Azizan Baharudin et.al. Kuala Lumpur: Pusat Dialog Peradaban Universiti Malaya, 2009. 